\title{
KORELASI PENDIDIKAN KARAKTER DAN SIKAP BELA NEGARA DENGAN SIKAP NASIONALISME PADA SISWA KELAS VII SMP N 1 COLOMADU TAHUN PELAJARAN 2018/2019
}

\author{
Oleh: \\ Irmawati Pratiwi $^{1)}$, Sugiaryo $^{2)}$, Anita Trisiana ${ }^{3)}$ \\ ${ }^{1)}$ Mahasiswa PPKn \\ ${ }^{2)}$ Dosen Prodi PPKn FKIP UNISRI \\ 3) Dosen Prodi PPKn FKIP UNISRI
}

\begin{abstract}
ABSTRAK
Tujuan penelitian ini adalah 1). Untuk mengetahui ada tidaknya korelasi antara pendidikan karakter dengan sikap nasionalisme pada siswa kelas VII SMP N 1 Colomadu tahun pelajaran 2018/2019. 2). Untuk mengetahui ada tidaknya korelasi antara sikap bela Negara dengan sikap nasionalisme pada siswa kelas VII SMP N 1 Colomadu tahun pelajaran 2018/2019. 3). Untuk mengetahui ada tidaknya korelasi antara pendidikan karakter dan sikap bela Negara dengan sikap nasionalisme pada siswa kelas VII SMP N 1 Colomadu tahun pelajaran 2018/2019. SMP N 1 Colomadu terletak di jalan Adi Sumarmo No. 51, Klolokan Rt 01/ Rw 01 Kelurahan Gawanan, Kecamatan Colomadu, Kota Karanganyar.

Metode penelitian yang digunakan adalah penelitian korelasional. Populasi dalam penelitian ini adalah semua siswa kelas VII SMP N 1 Colomadu Tahun Pelajaran 2018/2019 yang berjumlah 220 siswa. Sampel yang digunakan dalam penelitian ini yaitu berjumlah 55 siswa. Teknik pengambilan sampel dalam penelitian ini menggunakan teknik Proportional Random Sampling. Teknik pengumpulan data menggunakan angket dan dokumentasi. Teknik analisis data menggunakan uji korelasi product moment dankorelasi ganda.

Berdasarkan hasil analisis data diperoleh kesimpulan sebagai berikut: 1) Korelasi antara Pendidikan Karakter dengan Sikap Nasionalisme pada Siswa Kelas VII SMP N 1 Colomadu Tahun Pelajaran 2018/2019 menunjukkan bahwa nilai $\mathrm{r}_{\mathrm{x} 1 \mathrm{y}}=0,944$ $>\mathrm{r}$ tabel $5 \%=0,266$. Dengan demikian hipotesis yang menyatakan bahwa: "Terdapat hubungan yang positif dan signifikan antara Pendidikan Karakter dengan Sikap Nasionalisme pada siswa kelas VII di SMP Negeri I Colomadu tahun pelajaran 2018/2019" terbukti kebenarannya. 2) Korelasi antara Sikap Bela Negara dengan Sikap Nasionalisme pada Siswa Kelas VII SMP N 1 Colomadu Tahun Pelajaran 2018/2019 menunjukkan bahwa nilai $\mathrm{r}_{\mathrm{x} 2 \mathrm{y}}=0,989>\mathrm{r}$ tabel $5 \%=0,266$. Dengan demikian hipotesis yang menyatakan bahwa: "Terdapat hubungan yang positif dan signifikan antara Sikap Bela Negara dengan Sikap Nasionalisme pada siswa kelas VII di SMP Negeri I Colomadu tahun pelajaran 2018/2019" terbukti kebenarannya. 3) Korelasi antara Pendidikan Karakter dan Sikap Bela Negara dengan Sikap Nasionalisme pada Siswa Kelas VII SMP N 1 Colomadu Tahun Pelajaran 2018/2019 menunjukkan bahwa nilai $\mathrm{Rx}_{\mathrm{x} \times 2 \mathrm{y}}=0,984>\mathrm{r}$ tabel $5 \%=0,266$. Dengan demikian hipotesis yang menyatakan bahwa: "Terdapat hubungan yang positif dan signifikan antara Pendidikan Karakter dan Sikap Bela Negara dengan Sikap Nasionalisme pada siswa kelas VII di SMP Negeri I Colomadu tahun pelajaran 2018/2019" terbukti kebenarannya.
\end{abstract}

\section{Kata Kunci: Pendidikan Karakter, Sikap Bela Negara, Sikap Nasionalisme}




\begin{abstract}
The research aims at (1) finding out whether there is a correlation between character education with nasionalism in the seventh grade student at SP N 1 Colomadu in the academic year of 2018/2019 (2) finding out whether there is a correlation between state defense with nasionalism in the seventh grade student at SP $N$ 1 Colomadu in the academic year of 2018/2019 (3) finding out whether there is a correlation between character education and state defense with nasionalism in the seventh grade student at SP N 1 Colomadu in the academic year of 2018/2019. SMP N 1 Colomadu is located in Adi Sumarmo street No. 5, Klolokan, Gawanan, Colomadu district,Karanganyar regency.

The type of research is correlational research. The population of this research are all students of VII class SMP N 1 Colomadu in the 2018/2019 academic year which consist of 220 students. The sample used in this research were 55 students. The sampling technique used in this research was Proportional Random Sampling technique. The technique of collecting the data used questionnaire and documentation. The technique of analysis data used product moment correlation test and multiple correlation.

Based on the research findings, the following conclusions are obtained: 1) the correlation between character education with nasionalism in students of seventh class SMP N 1 Colomadu in the 2018/2019 academic year show that the value of $r_{x 1 y}=$ $0,944>r$ tabel $5 \%=0,266$. Therefore the hypothesis states that: "there is positive and significant correlation between character education with nationalism of students of seventh class SMP N 1 Colomadu in the 2018/2019 academic year" attested. 2) the correlation between state defense with nasionalism in students of seventh class SMP N 1 Colomadu in the 2018/2019 academic year shows that the value of $r_{x 2 y}=0,989>r$ tabel $5 \%=0,266$. Therefore the hypothesis states that: "there is positive and significant correlation between state defensewith nationalism of students of seventh class SMP N 1 Colomadu in the 2018/2019 academic year" attested. 3) the correlation between character education and state defense with nasionalism in students of seventh class SMP N 1 Colomadu in the 2018/2019 academic year show that the value of $r_{x 1 x 2 y}=0,984>r$ tabel $5 \%=0,266$. Therefore the hypothesis states that: "there is positive and significant correlation between character education and state defense with nationalism of students of seventh class SMP N 1 Colomadu in the 2018/2019 academic year" attested.
\end{abstract}

Keywords: Character Education, State Defense, Nationalism 


\section{PENDAHULUAN}

Dalam proses pendidikan di sekolah, kegiatan belajar mengajar merupakan hal yang paling penting. Proses belajar mengajar merupakan inti dari kegiatan pendidikan dalam mencapai tujuan Pendidikan Nasional, yaitu mencerdaskan kehidupan bangsa dan mengembangkan manusia seutuhnya, yaitu manusia yang beriman dan bertaqwa terhadap Tuhan Yang Maha Esa, dan berbudi pekerti luhur, memiliki pengetahuan dan keterampilan, sehat jasmani dan rohani, berkepribadian yang mantap dan mandiri, serta tanggung jawab kemasyarakatan

kebangsaan.Melalui Pendidikan Nasional diharapkan dapat meningkatkan mutu pendidikan dan martabat manusia Indonesia, sehingga pendidikan nasional dapat menghasilkan manusia yang terdidik, beriman, berpengetahuan, berketerampilan, dan memiliki rasa tanggung jawab (UU No. 20 Tahun 2003 tentang Sistem Pendidikan Nasional).Melalui Pendidikan Nasional diharapkan dapat menumbuhkan dan memperdalam rasa nasionalisme, memperkuat semangat kebangsaan serta bersikap dan berperilaku yang inovatif, sehingga mampu mewujudkan manusia yang dapat membangun dirinya sendiri serta bersama-sama bertanggung jawab atas pembangunan bangsa. Oleh karena itu, pendidikan karakter dan pengembangan sikap bela negara serta sikap nasionalisme sangat penting ditanamkan sejak dini kepada seluruh warga negara Indonesia. Salah satu sarananya adalah melalui pendidikan (Tilaar,
2000: 107). Namun pada kenyataannya, pencapaian tujuan pendidikan nasional masih dibilang jauh dari harapan. Bahkan dalam banyak hal justru memperlihatkan diantara komponen bangsa ini yang semakin kehilangan kejujuran, rasa kebangsaan, toleransi dalam menghadapi perbedaan, kedisiplinan serta rasa tanggung jawab sosial (Juwariyah, 2013: 36). Salah satu penyebabnya adalah pendidikan di Indonesia selama ini lebih menitik beratkan kepada pengembangan intelektual atau kognitif semata, sedangkan pengendalian diri, kepribadian serta akhlak mulia masih dianggap kurang penting dibandingkan dengan prestasi akademik.Padahal hal tersebut merupakan karakter yang harus dibentuk dalam proses pembelajaran, karena jika karakter tersebut tidak dibentuk sejak dini, maka dikhawatirkan dunia pendidikan hanya akan melahirkan manusia yang pintar namun tidak bermoral. Hal ini sesuai dengan penelitian Trisiana, A (2015) yang menyatakan bahwa:

Strategi pengembangan pendidikan karakter perlu terus dilakukan, pengembangan karakter budaya juga perlu dilakukan secara bersamaan, mengarah pada pembelajaran aktif, untuk mencapai aspek kognitif, afektif, dan psikomotor. Siswa diharapkan memiliki wawasan tentang negara, sikap sebagai bangsa, dan keterampilan yang signifikan untuk mengembangkan kehidupan pribadi, social dan nasional mereka.

Pendidikan

Karakter merupakan pendidikan yang mengembangkan karakter yang mulia (good character) dari peserta 
didik dengan mempraktekkan dan mengajarkan nilai-nilai moral dan pengambilan keputusan yang beradab dalam hubungan dengan sesama manusia maupun dalam hubungannya dengan Tuhannya (Samani dan Haryanto, 2012:44).Pendidikan ini fokus pada penanaman nilai dan penbentukan diri yang beragam dari segi agama, sosiokultural, bahasa, usia dan suku bangsa untuk menjadi warga Negara yang cerdas, terampil dan berkarakter yang diamanatkan oleh Pancasila dan UUD 1945 (Kurikulum Berbasis Kompetensi, 2004). Selain itu, siswa perlu dibekali dengan yang dinamakan sikap. Sikap disini mencakup tiga aspek, yaitu: pemahaman, penghayatan, dan pelaksaan. Ketiga aspek ini mutlak dimiliki siswa terutama dalam sikap bela negara dan sikap nasionalisme. Sehingga idealnya, Pendidikan Karakter dan sikap bela Negara menjadi landasan pembentukan sikap cinta tanah air dan penanaman nilai-nilai agar tercipta nasionalisme yang kuat. Namun, permasalahannya kondisi yang diharapkan belum terlihat di SMP N 1 Colomadu Tahun Ajaran 2018/2019. Hal ini terbukti dengan sikap dan perilaku sebagian siswa yang tidak mampu menghafal sila Pancasila, lagu-lagu nasional, namanama pahlawan, masih ada siswa yang kurang hidmat dalam melaksanakan Upacara Bendara, lunturnya rasa bangga terhadap bangsa Indonesia seperti gaya siswa yang mulai meniru K-Pop atau budaya asing, lebih memilih meggunakan Bahasa gaul dibandingkan Bahasa Indonesia serta lebih bangga menggunakan produk asing daripada menggunakan produk dalam negeri. Rosita (2013) mengatakan ciri-ciri Nasionalisme dibagai atas (1) memiliki rasa cinta tanah air; (2) bangga menjadi bagian dari Indonesia; (3) menempatkan kepentingan kelompok daripada kepentingan individu; dan (4) mengakui dan menghargai keanekaragaman. Hal ini sesuai dengan penelitian Trisiana, A (2017) yang menyatakan bahwa:

Pendidikan Karakter sangat diperlukan dalam membangun tanggungjawab sipil melalui perspektif multikulturalisme. Dalam keberagaman masyarakat diharapkan pendidikan karakter mampu menghadapi tantangan regional dan global.

Penelitian yang akan dilakukan ini mengacu pada penelitian sebelumnya yang diteliti oleh Ineu Rahmawati (2017) tentang "Efektivitas Pendidikan Bela Negara Dalam Peningkatan Sikap Nasionalisme Siswa Indonesia Di Community Learning Center Sarawak Malaysia", pada penelitian ini dijelaskan bahwa Pendidikan Bela Negara berpengaruh positif signifikan terhadap peningkatan Sikap Nasionalisme. Hal ini ditunjukkan dari partisipasi dan antusias siswa pada saat menerima materi bela Negara. Perbedaan dengan penelitian yang akan saya teliti adalah saya menambahkan variabel Pendidikan Karakter dan menjadikan Pendidikan Karakter dan Sikap Bela Negara sebagai variabel bebas. Oleh karena itu berdasarkan uraian di atas, peneliti mengambil penelitian dengan judul "Korelasi Pendidikan Karakter dan Sikap Bela Negara dengan Sikap Nasionalisme 
Pada Siswa Kelas VII SMP N 1

Colomadu Tahun Pelajaran 2018/2019".

\section{KERANGKA BERPIKIR}

Pendidikan saat ini mempunyai tantangan yang sangat besar, terkait masalah moral bangsa yang semakin menghawatirkan serta lunturnya sikap kebangsaan. Hal ini ditunjukkan dengan adanya tawuran antar pelajar, narkoba, demo mahasiswa yang berakhir ricuh dengan merusak fasilitas umum, sikap acuh terhadap guru atau orang yang lebih tua, dan sikap acuh terhadap keamanan dan kemerdekaan Negara. Hal ini disebabkan karena generasi muda tidak menjunjung nilai nasionalis dan persatuan bangsa. Oleh karena itu, pendidikan merupakan salah satu jalan untuk menyelesaikan masalah yang komplek tersebut. Oleh karena itu Wacana untuk diadakannya Pendidikan Karakter dan Sikap Bela Negara dianggap sangat tepat untuk menyelesaikan masalah tersebut. Pendidikan Karakter dan penanaman sikap bela Negara mulai dilaksanakan dalam dunia pendidikan dengan tujuan untuk memperkuat sikap nasionalisme siswa. Hal ini membuat peneliti tertarik untuk melakukan penelitian tengan Korelasi Pendidikan Karakter dan Sikap Bela Negara dengan Sikap Nasionalisme Pada Siswa Kelas VII SMP N 1 Colomadu Tahun Pelajaran 2018/2019. Berdasarkan uraian diatas maka peneliti membuat skema kerangka berfikir sebagai berikut:

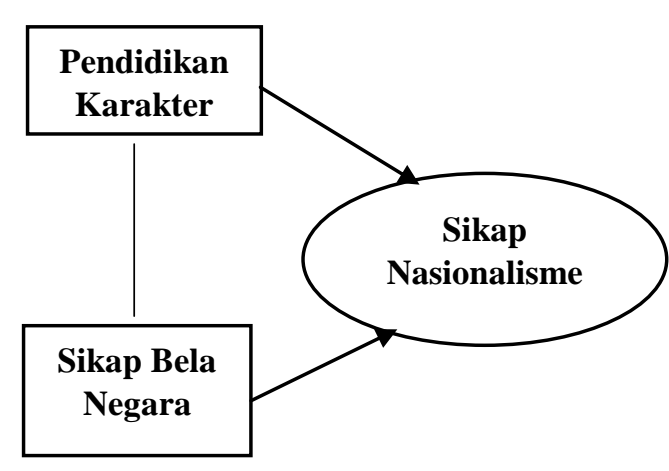

\section{Gambar 1. Skema Kerangka Berpikir}

\section{HIPOTESIS}

Berdasarkan uraian di atas, maka dapat dirumuskan hipotesis sebagai berikut.

1. Terdapat hubungan yang positif dan signifikan antara Pendidikan Karakter dengan Sikap Nasionalisme pada siswa kelas VII SMP Negeri 1 Colomadu.

2. Terdapat hubungan yang positif dan signifikan antara Sikap Bela Negara dengan Sikap Nasionalisme pada siswa kelas VII SMP Negeri 1 Colomadu.

3. Terdapat hubungan yang positif dan signifikan antara Pendidikan Karakter dan Sikap Bela Negara dengan Sikap Nasionalisme pada siswa kelas VII SMP Negeri 1 Colomadu. 


\section{METODE PENELITIAN}

Strategi Penelitian yang digunakan dalam penelitian ini adalah penelitian korelasional. Dalam penelitian ini terdapat tiga variabel yaitu dua variabel bebas dan satu variabel terikat. Menurut Umar (2006) variabel independen (bebas) adalah variabel yang menjelaskan atau mempengaruhi variabel yang lain sedangkan variabel dependen (tergantung) adalah variabel yang dijelaskan atau yang dipengaruhi variabel independen. Populasi dalam penelitian ini adalah semua siswa kelas VII SMP N 1 Colomadu Tahun Pelajaran 2018/2019 yang berjumlah 220 siswa. Sampel yang digunakan dalam penelitian iniyaituberjumlah 55 siswa. Teknik pengambilan sampel dalam penelitian ini menggunakan teknik Proportional Random Sampling. Teknik pengumpulan data menggunakan angket dan dokumentasi. Teknik analisis data menggunakan uji korelasi productmoment dan analisis korelasi ganda.

\section{HASIL PENELITIAN}

\section{Deskripsi Data}

\section{Deskripsi Data tentang Pendidikan Karakter}

Hasil penyebaran angket yang peneliti sampaikan pada kelas VII SMP N 1 Colomadu mengenai variabel pendidikan karakter diperoleh nilai tertinggi 137 dan nilai terendah 91. Adapun dari analisis data diperoleh nilai mean $=115,636$, median $=115,875$, modus $=$ 116,353 dan standar deviasi $=$ 12,545. Selanjutnya data hasil angket variabel pendidikan karakter tersebut dapat digambarkan dalam tabel frekuensi sebagai berikut:

Tabel 5

Distribusi Frekuensi Hasil Angket Variabel Pendidikan Karakter $\left(\mathbf{X}_{1}\right)$

\begin{tabular}{ccccccc}
\hline Nilai & $\mathbf{X}$ & $\mathbf{X}^{\mathbf{2}}$ & $\mathbf{f}$ & $\begin{array}{c}\text { Cf } \\
\mathbf{b}\end{array}$ & $\mathbf{f . X}$ & $\mathbf{f . X}^{\mathbf{2}}$ \\
\hline $\mathbf{9 1 - 9 7}$ & 94 & 8836 & 3 & 55 & 282 & 26508 \\
\hline $\mathbf{9 8 - 1 0 4}$ & 101 & 10201 & 8 & 52 & 808 & 81608 \\
\hline $\mathbf{1 0 5 - 1 1 1}$ & 108 & 11664 & 12 & 44 & 1296 & 139968 \\
\hline $\mathbf{1 1 2 - 1 1 8}$ & 115 & 13225 & 12 & 32 & 1380 & 158700 \\
\hline $\mathbf{1 1 9 - 1 2 5}$ & 122 & 14884 & 8 & 20 & 976 & 119072 \\
\hline $\mathbf{1 2 6 - 1 3 2}$ & 129 & 16641 & 2 & 12 & 258 & 33282 \\
\hline $\mathbf{1 3 3 - 1 3 9}$ & 136 & 18496 & 10 & 10 & 1360 & 184960 \\
\hline Jumlah & 805 & 93947 & 55 & & 6360 & 744098 \\
\hline
\end{tabular}

\section{Deskripsi Data tentang Sikap Bela Negara $\left(\mathbf{X}_{2}\right)$}

Berdasarkan hasil penyebaran angket yang peneliti sampaikan pada kelas VII di SMP Negeri I Colomadu Surakarta tahun pelajaran 2018/2019 mengenai sikap bela negaradiperoleh nilai tertinggi 137 dan nilai terendah 93 Adapun dari analisis data diperoleh nilai mean $=116,490$ median $=118,555$ modus $=$ 122,685 dan standar deviasi $=$ 11,787. Selanjutnya data hasil angket variabel sikap bela negara pada siswa kelas VII di SMP Negeri I Colomadu tahun pelajaran 2018/2019, dapat digambarkan dalam tabel frekuensi sebagai berikut: 
Tabel 6

Distribusi Frekuensi Hasil Angket Variabel Sikap Bela Negara $\left(\mathbf{X}_{2}\right)$

\begin{tabular}{ccccccc}
\hline Nilai & $\mathrm{X}$ & $\mathrm{X}^{2}$ & $\mathrm{f}$ & $\mathrm{Cfb}$ & $\mathrm{f.X}$ & $\mathrm{f.X}$ \\
\hline $93-99$ & 96 & 9216 & 4 & 55 & 384 & 36864 \\
$100-106$ & 103 & 10609 & 8 & 51 & 824 & 84872 \\
$107-113$ & 110 & 12100 & 13 & 43 & 1430 & 157300 \\
$114-120$ & 117 & 13689 & 9 & 30 & 1053 & 123201 \\
$121-127$ & 124 & 15376 & 8 & 21 & 992 & 123008 \\
$128-134$ & 131 & 17161 & 10 & 13 & 1310 & 171610 \\
$135-141$ & 138 & 19044 & 3 & 3 & 414 & 57132 \\
\hline Jumlah & 819 & 97195 & 55 & & 6407 & 753987 \\
\hline
\end{tabular}

\section{Deskripsi Data tentang Sikap} Nasionalisme (Y)

Berdasarkan hasil penyebaran angket yang peneliti sampaikan pada kelas VII di SMP Negeri I Colomadu Surakarta tahun pelajaran 2018/2019 mengenai sikap nasionalismediperoleh nilai tertinggi 137 dan nilai terendah 93. Adapun dari analisis data diperoleh nilai mean $=115,854$ median $=107,117$ modus $=$ 89,571 dan standar deviasi $=$ 12,001. Selanjutnya data hasil angket variabel sikap nasionalisme pada siswa kelas VII di SMP Negeri I Colomadu tahun pelajaran 2018/2019, dapat digambarkan dalam tabel frekuensi sebagai berikut:

Tabel 7.

Distribusi Frekuensi Hasil Angket Variabel sikap nasionalisme (Y)

\begin{tabular}{ccccccc}
\hline Nilai & X & $\mathrm{X}^{2}$ & f & Cfb & f.X & f.X \\
\hline $93-99$ & 96 & 9216 & 4 & 55 & 384 & 36864
\end{tabular}

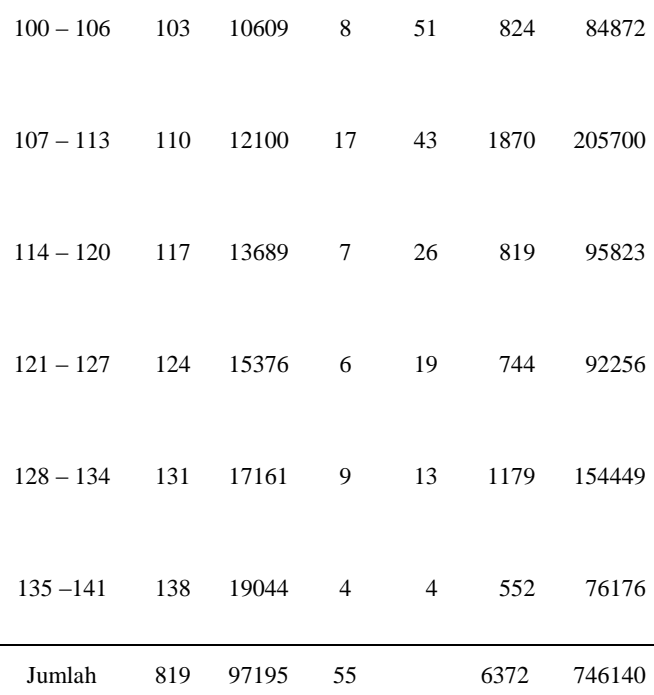

\section{PENGUJI HIPOTESIS}

1. Hubungan antara Pendidikan Karakter dengan Sikap Nasionalisme

Berdasarkan hasil analisis data mengenai hubungan antara pendidikan karakter dengan sikap nasionalisme pada siswa kelas VII di SMP N 1 Colomadu Tahun Pelajaran 2018/2019yang dianalisis dengan menggunakan korelasi $r$ product moment diperoleh nilai $r$ hitung yaitu $r_{x 1 y}$ $=0,944$. Selanjutnya nilai $r_{x 1 y}$ dibandingkan dengan nilai $r$ tabel $\mathrm{N}=55$ signifikan $5 \%=$ 0,266 .

Hasil analisis menunjukkan bahwa nilai $r_{x 1 y}=0,944>r$ tabel $5 \%=0,266$. Dengan demikian hipotesis yang menyatakan bahwa: "Terdapat hubungan yang positif dan signifikan antara pendidikan karakter dengan sikap nasionalisme pada siswa kelas VII di SMP N 1 Colomadu Tahun Pelajaran 2018/2019" terbukti kebenarannya. 


\begin{abstract}
Dengan demikian dapat peneliti kemukakan bahwa semakin baik pendidikan karakter yang dimiliki oleh siswa kelas VII SMP Negeri 1 Colomadu Tahun Pelajaran 2018/2019 maka semakin baik pula sikap nasionalisme siswa.
\end{abstract}

2. Hubungan antara Sikap Bela Negara dengan Sikap Nasionalisme pada siswa kelas VII SMP N 1 Colomadu Tahun Pelajaran 2018/2019

Berdasarkan hasil analisis data mengenai hubungan antara pendidikan karakter dengan sikap nasionalisme pada siswa kelas VII di SMP N 1 Colomadu Tahun Pelajaran 2018/2019yang dianalisis dengan menggunakan korelasi $r$ product moment diperoleh nilai $r$ hitung yaitu $r_{x 2 y}$ $=0,989$. Selanjutnya nilai $\mathrm{r}_{\mathrm{x} 2 \mathrm{y}}$ dibandingkan dengan nilai $\mathrm{r}$ tabel $\mathrm{N}=55$ signifikan $5 \%=$ 0,266 .

Hasil analisis menunjukkan bahwa nilai $r_{x 2 y}=0,989>r$ tabel $5 \%=0,266$. Dengan demikian hipotesis yang menyatakan bahwa: "Terdapat hubungan yang positif dan signifikan antara sikap bela negara dengan sikap nasionalisme pada siswa kelas VII di SMP N 1 Colomadu Tahun Pelajaran 2018/2019" terbukti kebenarannya.

Dengan demikian dapat peneliti kemukakan bahwa semakin baik Sikap Bela Negara yang dimiliki oleh siswa kelas VII SMP Negeri 1 Colomadu Tahun Pelajaran 2018/2019 maka semakin baik pula sikap nasionalisme siswa.

3. Hubungan antara Pendidikan Karakter dan Sikap Bela Negara dengan Sikap Nasionalisme pada siswa kelas VII SMP N 1 Colomadu Tahun Pelajaran 2018/2019

Berdasarkan hasil analisis data mengenai hubungan antara pendidikan karakter dengan sikap nasionalisme pada siswa kelas VII di SMP N 1 Colomadu Tahun Pelajaran 2018/2019yang dianalisis dengan menggunakan korelasi ganda diperoleh nilai $\mathrm{r}$ hitung yaitu $r_{x 1 \times 2 y}=0,984$. Selanjutnya nilai $r_{x 1 \times 2 y}$ dibandingkan dengan nilai $r$ tabel $\mathrm{N}=55$ signifikan $5 \%=$ 0,266 .

Hasil analisis menunjukkan bahwa nilai $\mathrm{r}_{\mathrm{x} 1 \mathrm{x} 2 \mathrm{y}}$ $=0,984>\mathrm{r}$ tabel $5 \%=0,266$. Dengan demikian hipotesis yang menyatakan bahwa: "Terdapat hubungan yang positif dan signifikan antara pendidikan dan sikap bela negara dengan sikap nasionalisme pada siswa kelas VII di SMP N 1 Colomadu Tahun Pelajaran 2018/2019" terbukti kebenarannya.

Dengan demikian dapat peneliti kemukakan bahwa semakin baik Pendidikan Karakter dan Sikap Bela Negara yang dimiliki oleh siswa kelas VII SMP Negeri 1 Colomadu Tahun Pelajaran 2018/2019 maka semakin baik pula sikap nasionalisme siswa. 


\section{PEMBAHASAN}

Berdasarkan hasil uji hipotesis di atas pada taraf signifikansi 5\% diperoleh bahwa ada hubungan yang positif dan signifikan antara "Pendidikan Karkter dan Sikap Bela Negara dengan Sikap Nasionalisme pada siswa kelas VII di SMP Negeri I Colomadu Tahun Pelajaran 2018/2019" diterima kebenarannya dan Hipotesis Nol atau nihil (Ho) yang menyatakan "Tidak ada hubungan yang positif dan signifikan antara Pendidikan Karkter dan Sikap Bela Negara dengan Sikap Nasionalisme pada siswa kelas VII di SMP Negeri I Colomadu Tahun Pelajaran 2018/2019 di tolak. Berdasarkan hasil tersebut maka dapat disimpulkan bahwa pendidikan karakter dan sikap bela Negara memiliki hubungan yang sangat erat dengan sikap nasionalisme. Menurut No. 20 Tahun 2003 tentang Sistem Pendidikan Nasional, pendidikan karakter dan sikap bela Negara diharapkan dapat menjadikan peserta didik yang berperilaku baik, mampu membentuk bangsa yang bermoral, bertoleransi dan bekerja sama. Pembentukan karakter dan sikap bela negara harus dimulai dikembangkan di lembaga pendidikan sekolah, diterapkan secara nyata dalam masyarakat. Adapun proses untuk membentuk katakter dan sikap bela Negara yang baik dapat melalui: 1). Pemahaman (ilmu), dengan cara menginformasikan tentang hakikat dan nilai-nilai yang terkandung didalamnya, pemahaman yang diberikan setiap saat sehingga dapat dipahami dan diyakini bahwa obyek itu benar-benar berharga dan bernilai. Dengan demikian akan menimbulkan rasa tertarik dalam hatinya sehingga peserta didik akan melakukan perbuatan yang baik dikeseharianya sesuai dengan apa yang ia pahami dan yakini. 2). Pembiasaan (amal). Dengan kata lain, pembentukan karakter dan sikap bela negara yang baik harus melibatkan bukan saja aspek "pengetahuan yang baik (moral iknowing), akan tetapi juga "merasakan dengan baik atau loving good (moral feeling), dan perilaku yang baik (moral action). Sehingga dengan terbentuknya karakter dan sikap bela negara yang baik maka akan timbul sikap nasionalisme pada siswa dalam kehidupan sehari-hari.

\section{KESIMPULAN DAN SARAN}

\section{Kesimpulan}

Berdasarkan hasil analisis data mengenai hubungan antara pendidikan karakter dengan sikap nasionalisme pada siswa kelas VII di SMP N 1 Colomadu Tahun Pelajaran 2018/2019 diperoleh nilai $r$ hitung yaitu $\mathrm{r}_{\mathrm{x} 1 \mathrm{y}}=0,944>\mathrm{r}$ tabel $5 \%=$ 0,266 . Dengan demikian hipotesis yang menyatakan bahwa: "Terdapat hubungan yang positif dan signifikan antara pendidikan karakter dengan sikap nasionalisme pada siswa kelas VII di SMP N 1 Colomadu Tahun Pelajaran 2018/2019" terbukti kebenarannya.

Berdasarkan hasil analisis data mengenai hubungan antara sikap bela negara dengan sikap nasionalisme pada siswa kelas VII di SMP N 1 Colomadu Tahun Pelajaran 2018/2019 diperoleh nilai $r$ hitung yaitu $r_{x 2 y}=0,989>r$ tabel $5 \%=$ 
0,266. Dengan demikian hipotesis yang menyatakan bahwa: "Terdapat hubungan yang positif dan signifikan antara sikap bela negara dengan sikap nasionalisme pada siswa kelas VII di SMP N 1 Colomadu Tahun Pelajaran 2018/2019" terbukti kebenarannya.

Berdasarkan hasil analisis data mengenai hubungan antara sikap bela negara dengan sikap nasionalisme pada siswa kelas VII di SMP N 1 Colomadu Tahun Pelajaran 2018/2019 diperoleh nilai $r$ hitung yaitu $r_{x 1 \times 2 y}=0,984>r$ tabel $5 \%=$ 0,266 . Dengan demikian hipotesis yang menyatakan bahwa: "Terdapat hubungan yang positif dan signifikan antara pendidikan pendidikan dan sikap bela negara dengan sikap nasionalisme pada siswa kelas VII di SMP N 1 Colomadu Tahun Pelajaran 2018/2019" terbukti kebenarannya.

\section{Saran}

Saran yang diajukan penulis dalam penelitian ini adalah sebagai berikut:

1. Mengingat belum semua guru dapat menerapkan dan menjadi teladan dalam pembentukan karakter dan sikap bela negara secara penuh, maka hendaknya pihak sekolah memberikan fasilitas berupa forum diskusi guna memberikan arahan kepada guru untuk dapat menerapkan pehamaman tentang sikap bela Negara dan pembentukan karakter secara maksimal, supaya terciptanya sikap nasionalisme siswa yang baik.

2. Guru hendaknya dalam menanamkan pengetahuan pada siswa, jangan hanya pada ranah kognitif saja, tetapi juga pembentukan karakter dan sikap bela negara yang baik agar anak mempunyai sikap nasionalisme kedepannya.

3. Bagi siswa agar lebih mendalami lagi apa itu karakter dan sikap bela negara bagaimana keduanya bekerja. Dengan memahami tentang keduanya, maka diharapkan siswa akan memliki karakter dan sikap nasionalisme yang lebih baik lagi.

4. Dengan adanya penelitian ini, diharapakan peneliti dapat terus menerus membantu guruguru dan sekolah menemukan solusi penanaman karakter, sikap bela negara dan sikap nasionalisme siswa di sekolah khususnya SMP Negeri I Colomadu tahun pelajaran 2018/2019.

\section{DAFTAR PUSTAKA}

Abdullah, $\quad$ Taufik. 2001. Nasionalisme Dan Sejarah. Bandung: Satya Historika

Aman. 2011. Model Evaluasi Pembelajaran Sejarah. Yogyakarta: Ombak

Anomin. 2014. Jalan Perubahan Untuk Indonesia Berdaulat, Mandiri, danBerkepribadian: Visi, Misi, dan Program Aksi.

Darmadi, Hamid, 2010. Pengantar Pendidikan

Kewarganegaraan., Bandung:Alfabeta. 
Juwariah, 2013. Pendidikan Karakter dalam perspektif pendidikanIslam. Yogyakarta: Fakultas Ilmu Tarbiyah dan Keguruan UIN Sunan Kalijaga.

Kartodirdjo, Sartono. 1994. Pembangunan Bangsa, Nasionalisme, Kesadaran Sejarah, dan Kebudayaan Nasional. Jakarta: Gramedia Pustaka Utama.

Kemendiknas. 2010. Pengembangan Pendidikan Budaya Dan Karakter Bangsa Pedoman Sekolah. Jakarta.

Muchlas dan Haryanto. 2011. Konsep Dan Model Pendidikan Karakter. Bandung: PT Remaja Rumah. Yogyakarta: Pustaka Insan Madani.Rasdakarya.

Munir, Abdullah. 2010. Pendidikan Karakter Membangun Karakter Anak Sejak Dari

Rahmawati, Ineu. 2017. Efektivitas Pendidikan Bela Negara Dalam Peningkatan Sikap Nasionalisme Siswa Indonesia Di Community Learning Center Sarawak Malaysia. Jurnal Program Studi Pertahanan. 3(1).

Rosita. 2013. Hubungan Pemahaman Bela Negara dengan Nasionalisme Siswa di SMP Negeri 3 Tambun: FKIP UNJ.
Samani, Muchlas. 2012. Konsep Dan Model Pendidikan Karakter, Bandung: Remaja Rosdakarya.

Sugiyono. 2010. Metode Penelitian Pendidikan Pendekatan Kuantitatif Kualitatif dan $R \& D$. Bandung: Alfabeta.

Sugiono. 2015. Metode Penelitian Kuantitatif, Kualitatif dan $R \&$ $D$. Bandung: Alfabeta.

Suharsimi Arikunto. 2015. DasarDasar Evaluasi Pendidikan. Jakarta. Bumi Aksara.

Suharsimi Arikunto. 2006. Prosedur Penelitian Suatu Pendekatan Praktik, Jakarta: PT Rineka Cipta.

Sujarno, 2013. Pemanfaatan Permainan Tradisional Dalam Pembentukan Karakter Anak, Yogyakarta: Balai Pelestarian Nilai Budaya (BPNB).

Sukmadinata. 2007. Metode Penelitian Pendidikan, Bandung: Remaja Rosda Karya.

Taniredja. 2010. Pendidikan Kewarganegaraan Paradigma Terbaru Untuk Mahasiswa. Bandung: Alfabeta.

Tilaar, H.A.R. 2000. Pendidikan, Kebudayaan, dan masyarakat Madani Indonesia: Strategi Reformasi Pendidikan Nasional. Bandung: PT Remaja Rosdakarya.

Trisiana, Anita. 2015. The Development Strategy 
OfCitizenship Education In Civic Education Using Project Citizen Model In Indonesia.JPER. 23(2). 112.

Trisiana, Anita. 2017. The Challenges For The Development Of Character Education In Building Civic Responsibility Through Multiculturalism Perspective. Proceedings. ICTESS UNISRI 2017, Vol 1(1).

Umar, H. 2006. In Metodologi Penelitian (p. 63). Jakarta: Raja Grafind. 